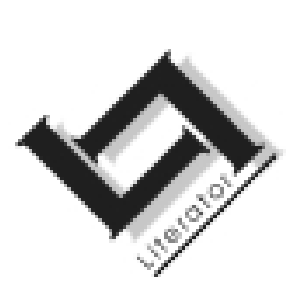

\title{
Language through literature through language: An action research report on the English 100 course at the University of North West
}

\author{
I. Butler
}

Department of English

University of North West

MAFIKENG

E-mail: impala@netactive.co.za

\begin{abstract}
Language through literature through language: An action research report on the English 100 course at the University of North West
\end{abstract}

In this article the writer surveys attitudes to the integration of language and literature in ESL/EFL teaching, noting the reservations that have been expressed about it in the past, and which still continue to linger in some quarters. Against this background he then describes the development and implementation of an integrated English syllabus at the University of North West, focusing on his current action research in teaching the first year modules. Using examples from the material he has developed for these modules, he demonstrates how the principles of language/literature integration, as articulated by writers in the field, can be translated into practice in a number of ways. Since this is an on-going project the writer presents his findings as a report on work in progress. The article does, however, conclude with a brief summary of the positive responses received from lecturers and students in response to questionnaires and surveys conducted in 2000 and 2001.

A linguist deaf to the poetic function of language and a literary scholar indifferent to linguistic problems and unconversant with linguistic methods, are equally flagrant anachronisms.

Roman Jakobson (in Simpson, 1997:ii)

I imagined how it would be like to study literature alone. This would be tough especially if English is not your first language. Just tough.

(From the journal of an English 100 student, University of North West) 


\section{Introduction}

Jakobson's classic assertion of the inter-relatedness of language and literature studies, made in 1958, is reproduced in all the books in Routledge's current INTERFACE series. But an editorial comment under the quotation notes wryly:

This statement, made over twenty-five years ago, is no less relevant today, and 'flagrant anachronisms' still abound. The aim of the INTERFACE series is to examine topics at the 'interface' of language studies and literary criticism and in doing so to build bridges between these traditionally divided disciplines (Simpson, 1997:ii).

The way in which these bridges are built is clear from a survey of the books currently on offer in the series: titles such as Language through literature; Language, literature and critical practice; A linguistic history of English poetry; Feminist Stylistics and Literature about language point to the varied possibilities for exploring the interface between language and literature.

The INTERTEXT series, also published by Routledge, shows a similar blurring of the traditional divisions between the disciplines. The core workbook, Working with texts, offers a method of analysing a variety of texts, literary and non-literary. The more specialised satellite volumes bearing titles such as The language of fiction, The language of newspapers, The language of advertising, The language of sport and The language of poetry - attest to the common ground between language and literature studies.

But if Jakabson's 'flagrant anachronisms' continued to abound for some time in the academic study of language and literature, the same has been true in the more practical fields of ESL/EFL teaching. As Bassnett and Grundy (1993:1) put it:

We have encountered language teachers who think literature is irrelevant, who argue that what students need are texts that are 'practical' and 'rooted in everyday experience', not works of art. And we have encountered literature teachers who look down on 'mere language' work, as though literary texts were made from some ethereal matter and not constructed out of language at all.

In the following sections a brief survey will be made of changing attitudes to the integration of language and literature in EFL/ESL teaching, as they have been expressed on both sides of the language/ literature divide. 


\section{Literature in language teaching}

The attitude that literature is irrelevant to language teaching was succinctly and forcefully summed up by Blatchford $(1972: 1,6)$ thirty years ago. He rejects the study of English literature as "a luxury that cannot be indulged", an "expensive gew-gaw". It is far more important, he insists, that students be given every opportunity to develop communication skills. Blatchford does qualify these sweeping statements with an acknowledgement that they might not hold true in all situations, such as where English is taught as a second, rather than a foreign, language. His stance, nevertheless, seems to have been representative of a pervasive attitude to literature among writers and practitioners in the field of language teaching at that time. For example, Arthur (1968:199), writing a few years earlier, acknowledges the reluctance of language teachers to include literature in the syllabus, and Allen (1976:17) notes the deep division between linguistics and literature.

However, there were, at the same time, also voices claiming a place for literature in the language classroom. Marckwardt (1978:19), for example, argues that there is "a justifiable and a profitable place for literature" in $E S L$, adding that "the place and the purpose of a literary component within the English curriculum will differ with the place and the purpose of teaching English".

It has remained a contentious issue, however. Even in more recent years, nearly all writers advocating the use of literature in ESL/EFL preface their discussion with an acknowledgement of a widely held belief that literature does not have a place in language pedagogy. They then implicitly defend themselves against anticipated objections by pointing to recent changes in thinking. As recently as 2000, Bates (2000:13) felt it necessary to argue that poetry is not, as is often supposed, completely removed from learning or teaching a language:

In fact poetry can handle all kinds of experience connected with EFL and irradiate the experience, providing thought or comic relief, making the experience more real, and perhaps making the language learning more creative.

Nevertheless, in spite of lingering reservations, there has been an increased interest in using literature in language teaching in recent years. McRae, himself a prolific contributor to the field, announces that literature "has made a widely heralded comeback", and goes on to offer an analysis of the "buzzwords" that have inevitably accompanied its reappearance in EFL pedagogy (McRae, 1991:432). Lazar (1994:115) also comments on the growth of interest in the previous decade. Publications since then indicate that the interest in literature has con- 
tinued - as has the debate about its relevance and application. Paran (1998:6) welcomes the "comeback" of literature, while at the same time pointing out that most ESL teachers are not well trained to teach literature. Both scholarly and professional publications have explored the theoretical and practical possibilities of literature in the language classroom; a number of course books and teacher training manuals have appeared, giving concrete expression to these ideas.

\section{Language in literary studies}

But the initiative for integration has not only come from the language classroom. Various factors in recent years have undermined the position of literature as an area of language use divorced from others. The privileged status traditionally given to literary texts in the study of a language has increasingly been replaced with a more utilitarian bias which favours language for its instrumental benefits - now the very inclusion of literature in the syllabus is a matter of debate.

This process has certainly been evident in the changing face of English studies at South African universities. Combrink (1996:3), in describing innovations to the English programme at Potchefstroom University, sketches in the following brief background to the changes:

English departments in South Africa have traditionally been departments of English literature (firmly along the lines of the Oxbridge model), with the lang/lit divide providing grounds for at times acrimonious debate. In the past decade and a half, however, it has increasingly become imperative to address the teaching of students at tertiary level in a way at once more 'practical' and 'relevant' without relinquishing the perceived benefits of a 'liberal' education.

"Practicality" and "relevance" have been interpreted in various ways. For some it has simply meant an opening out of the literary canon to include texts previously excluded. Another response has been to argue for an equal place for language study in the curriculum. Pereira (1990:114), reviewing the proceedings of the Conference on English at Tertiary Level in 1989, a forum in which issues such as these were discussed, draws special attention to the language/literature debate, emphasising the need for a change from the traditional "Oxbridge" model:

If one point has emerged with crystal clarity, it is that Departments of English can no longer ignore the need to involve themselves in language teaching. It is not merely a responsibility, it is becoming a matter of survival. 
Survival has become a matter of increasing concern to South African universities in the years that have elapsed since then. English has fared better than many other disciplines, but only because of the perceived instrumental benefits that the language offers to ESL students. Pereira's argument is now even more compelling than ever, in spite of lingering perceptions of literature's superiority to the more mundane business of actually teaching the language. This view is, by no means confined to South African universities. As McRae (1997:120) comments:

Too often, in university systems all over the world, literature study is not related to language learning; one is considered something of a superior discipline, the other an inferior exercise often entrusted to lower-level personnel.

\section{Integrating language and literature in EFL/ESL}

The preceding sections have suggested a growing awareness by both language and literature teachers that each discipline can contribute to the effective teaching of the other. Such recognition opens the way for the systematic integration of the two.

The possibilities for the integration of language and literature are nicely captured by Carter (1985:9) and Tomlinson (1985:9) in two articles in the EFL Gazette, under the shared heading, "Language through literature and literature through language". The phrase suggests two contrasting pedagogical foci ("language" and "literature") and the vehicle ("through") by which they might be presented to the learner ("literature" and "language"). The symmetrical reversal of the elements on either side of the conjunction neatly captures the possibilities for integration. The catch-phrase has been taken up in numerous subsequent studies (see for example Bassnett \& Grundy 1993; Simpson 1997).

Tomlinson argues in favour of using literature as a resource in the teaching of language ("language through literature"). He suggests a number of advantages to this approach:

Poems, stories and extracts from plays, novels and autobiographies can involve students as individual human beings who can gain rich exposure to authentic English as well as opportunities to develop communication skills as a result of motivated interaction with texts and with their fellow students.

Carter, on the other hand, presents the case for a stylistic approach to literature ("literature through language"). Referring specifically to the context of "the teaching of literature to non-native speaking undergraduate students of English" he claims that stylistics "is an approach to 
texts which allows ideas, intuitions and initial interpretations to be explored by a inguistically principled analysis of the functions of grammar, lexis, phonology and discourse in the creation of meaning". He concludes confidently that it is "undoubtedly the case that students"" response to literature varies in proportion to their sensitivity to language use".

These two broad approaches have been elaborated by various writers in the field. "Language through literature" has included using literary texts as resources for grammar teaching and raising language awareness. "Literature through language" has included the use of "pre-literary activities" such as cloze, multiple-choice, jig-saw reading and practical stylistics. The general consensus is that the integration of language and literature has a positive effect on the teaching and learning of both components: Carter and Long (1991:101) suggest that the integration of literature and language studies can do "as much for the language development of the student as for the development of capacities for literary understanding and appreciation".1

\section{English at the University of North West: A case study}

The Department of English at the University at the North West has always recognised that both language and literature are important components in a programme of English studies, especially one aimed at second-language speakers of English.

When the university was established in 1980 as the University of Bophuthatswana it was stated that "the university should not necessarily follow the pattern of the classical Western university, but should seek to establish a university structure that would be relevant to the needs of the country [i.e. the then nominally independent republic of Bophuthatswana]" (University of Bophuthatswana, 1980:14). Relevance here included a recognition of the needs of students studying through the medium of a second language, English; and a vocational focus which meant that "curricula and educational methods [were] designed with

1 Space does not permit a detailed survey of the many publications in this area of English teaching, both scholarly and professional. Widdowson (1975, 1992), Brumfit (1983), Brumfit and Carter (1986), Collie and Slater (1987), Carter et al. (1989), Maley and Duff (1989), Duff and Maley (1990), Carter and Long (1987, 1991), McRae (1997), Lazar (1993), Pope (1998) and Norman (1998) - to name only a few - have all made important contributions to the theory and practice of integrating language and literature, effectively dispelling any reservations that many practitioners might still have about the suitability of the approach for speakers of English as a second or foreign language. 
requirements of the future work situation or vocational field in mind" (University of Bophuthatswana, 1980:21).

These innovations had specific consequences for the fledgling Department of English. The requirement that students be provided with academic support in language and study skills led to the establishment of the Special English (SPEN) unit which offered a compulsory, non-continuing course to all first year students (see Murray, 1990). The vocational bias meant that the Department was situated within the School of Education, and offered a four year programme which included ESL teaching methodology. Initially students were given the option of majoring in either literature or language; later it was decided that both should be offered, since both disciplines represented skills necessary for prospective teachers. A three year B.A. programme was offered in later years, which also combined language and literature but had components in research methodology instead of the teaching methods offered to the B.A. (Ed.) students.

The importance attached to language studies (in contrast to the literary bias at most other South African universities) may be deduced from the words of a former Professor of English Literature at the University of Bophuthatswana. In a paper delivered at the South African Applied Linguistics Association in 1991, Professor Walter Saunders spoke of the choice of literary texts for study in an ESL situation, linking the issue to the need for literary and linguistic competence:

Until there is considerable language mastery and until there is considerable experience of current literature, reflecting current, even local, issues and concerns, there is little sense in compelling students to grapple with books about remote events, written in a highly complex and antiquated style (for example, Dickens, George Eliot and Thomas Hardy). Until language mastery is achieved, the teaching of literature should occupy a secondary place, and books should to a large extent be prescribed for their usefulness in achieving that mastery. They should help reinforce the process of learning the language as a current medium of expression (Saunders, 1991:3).

By the late 1990s, however, staff in the Department had perceived the need for a radical reassessment of the syllabus. The integration and balance of language and literature especially was a cause for concern among some lecturers (Butler, 1999:36). Relations between "language lecturers" and "literature lecturers" lacked the acrimony mentioned by Combrink (1996:3), but they were generally characterised by indifference to and ignorance of the others' work. Little attempt was made to coordinate the parallel streams, apart from allocating separate lecturing slots on the timetable. Language and literature were taught and 
examined separately. Students often complained of the conflicting demands made on them by language and literature lecturers. Assessment criteria and grades were often perceived as being unfairly inconsistent.

There was also the perennial problem of reconciling the demands of the academic disciplines on the one hand, with the need to develop fairly elementary linguistic skills on the other. In practical terms this meant balancing various (usually conflicting) options. To what extent did "language" mean "knowledge about language" as opposed to the development of practical communication skills? To what degree could the study of literary genres, periods or authors be made compatible with the development of basic reading skills and literary competence?

Coinciding with these internal pressures were calls from the national Ministry of Education for universities to revise their programmes in line with the move towards outcomes-based education and modularization.

Whereas, in the publications surveyed earlier, the debates hinged on whether or not literature or language should be included in existing syllabi as a balance to their traditional focus, at the University of North West the inclusion of both components was taken as a given. The challenge in developing a new syllabus lay in finding ways of integrating them so that each could benefit from and be enriched by the other, and at the same time satisfy the conflicting demands of an ESL syllabus.

With all these factors in mind, a new undergraduate programme was drawn up, and the first steps towards implementation were made in 1998. By 2000 a fully modularized programme based on the principle of the integration of language and literature was in place.

The importance of the first year of university study has become a commonplace in South Africa (see for example Chapman, 1990; Orr, 1997). It is for this reason that I chose the first year modules as the focus for an action research project in which to examine the integration of language and literature within the discipline of English studies. The remainder of this article will be devoted to a description of the English 100 modules and an account of my ongoing attempts to translate the principles of language/literature integration into practice through the development of appropriate materials and teaching methodology.

\section{Action research: Methodology}

The case study described here is conducted within the paradigm of action research. Yin (1994:13) defines a case study as "an empirical inquiry that investigates a contemporary phenomenon within its real-life 
context". The relationship between research and the context in which it is sited is also implied in the definition of action research given by Cohen and Manion (1994:186): a "small scale intervention in the functioning of the real world and a close examination of the effects of such intervention". A further dimension to action research is that it conflates the roles of practitioner and researcher: research questions emerge from the practitioner's immediate concerns and problems. The aim of the research is not merely to analyse and explain, but also to improve on the practice. Nunan (2001:198) uses the term "reflective practice" to describe action research, emphasising the link between research and professional development. He also warns that action research is "difficult, messy, problematic, and in some cases, inconclusive" (Nunan, 2001:202).

It was with these principles - and Nunan's caveat - in mind that I undertook the research.

\section{English 100: A description of the modules}

The first year course consists of four eight week modules:

ENG 101: Introduction to English studies

ENG 102: Introduction to textual analysis

ENG 103: Introduction to literary genres

ENG 104: Grammar awareness

In the first two modules the literature and language streams are completely integrated. In ENG 103 and ENG 104 they are separated, each module having a clear bias towards either literature or language. Integration is, however, achieved through links made between the two modules. Both forms of integration - intra- and inter-modular - are employed throughout the undergraduate programme.

\subsection{ENG 101: Introduction to English studies}

The first module serves as an introduction both to the first year of study and to English studies generally. Its main aim is to raise and develop the students' language awareness, and develop the skills of reflection, observation and analysis that they will need later in their studies. A wide range of topics is touched upon, but the intention is to be as practical as possible, and to introduce new concepts and ideas by drawing on and developing the students' existing knowledge and experience.

It is here that the integration of language and literature plays a valuable role. The topics in the module have a bias towards applied linguistics and knowledge about language, but literature is also present in the form of the texts through which the subject matter is introduced and illustrated. 
Literature, in other words, is used to provide a direct, concrete and - to borrow Sir Philip Sidney's phrase - delightful way of approaching and illustrating abstract concepts. Literature thus becomes a vehicle for promoting affective learning (McRae, 1991:3). A few examples may illustrate this:

- Christopher van Wyk's "On learning Sotho" used as an introduction to the topic, "Learning and knowing a language";

- R.K Narayan's short story, "The Mute Companions" used to demonstrate the use of non-verbal communication;

- extracts from works by writers such as Chinua Achebe, Athol Fugard and V.S Naipaul to illustrate some of the varieties of English found throughout the world;

- a passage from Pygmalion (a controversial choice of text, but one that worked quite well) to illustrate differences in style and register, and their appropriate social use (making polite conversation about the weather is not the same as giving a detailed weather forecast - as Eliza, in spite of her impeccable accent, failed to realise!)

At the same time students are encouraged to appreciate these texts as literary texts; in this way the foundations for literary as well as linguistic competence are laid in the first module.

\subsection{ENG 102: Introduction to textual analysis}

In the second module the relationship between language and literature is actually foregrounded, as it becomes the explicit object of study, as well as the implicit methodology. Whereas in ENG 101 a variety of texts, literary and non-literary, are used to illustrate and exemplify concepts in language, here the emphasis shifts to the texts themselves. Skills in recognising, reading and analysing different kinds of texts are developed. Through this process the awareness of language that was introduced in ENG 101 is further consolidated, as students are exposed to a wide variety of styles, registers and genres.

A significant influence on the theory underlying ENG 102 is the work by, among others, Carter and Long (1991:101) who propose the idea of a "scale or cline of literariness". Literature, they suggest, should not be seen as a phenomenon isolated from other language uses (as the more traditional approaches to the teaching of literature tend to imply); rather, "literariness" exists on a scale, with many kinds of discourse possessing some of the features usually associated with literary texts. Exposing students to a wide range of texts with varying degrees of "literariness" can therefore have the positive effect of demystifying literature, taking it 
down from its pedestal, and making it seem less intimidating to students lacking in literary experience. Literature becomes, as McRae (1991) suggests, "literature with a small 'l'”.

Comparing literary with "non-literary" texts enables students to see that although literary texts are, in many ways, "different", they also share many features with other, more familiar, discourses. This recognition, as Bassnett and Grundy (1993:2) point out, can provide them with a "way in" to literature. Texts such as advertisements, billboards and slogans are part of everyday life, yet they employ many of the techniques more usually associated with poetry, such as alliteration, assonance and parallelism.

On the other hand, some of the unique characteristics of literature can also be revealed through the technique of textual comparison and contrast. For example, one might compare T.S Eliot's "The Journey of the Magi" with the well-known Biblical story; or an extract from Achebe's novel Things fall apart with a passage from a history book describing the effects of colonialism on Africans.

\subsection{ENG 103 : Introduction to literary genres/ENG 104: Grammar awareness}

Stern (1991: 330) describes the integration of language and literature as an approach

... which integrates literature study with mastery of the language (vocabulary and grammar), with further development of the language skills (reading, writing, listening and speaking), and with increased awareness and understanding of British, American, and other English-speaking cultures.

She goes on to suggest

... that study of a single literary work can combine all the language
skills with one another, with exposure to American or British culture,
and with increased literary understanding and appreciation. Activities
focusing on each area can build upon and complement one another,
contextualizing all aspects of language learning.

This, broadly speaking, is the approach that underlies the conception of language/literature integration in ENG 103 and ENG 104. Instead of Stern's "awareness and understanding" of American and British cultures, however, students are exposed to topics of more general interest and relevance. 
Although ENG 103 and ENG 104 are described as literary and language modules respectively, integration is possible through the multiple use of texts, in the manner proposed by Stern. Literary texts, prescribed for the ENG 103 module can, in ENG 104, also serve as a stimulus for writing skills development and provide a meaningful context for the teaching of grammar.

Once again, an example will show how this kind of integration is possible. The idea of "narrative" could be used to link the two modules and at the same time take some of the bewildering mystique out of the literary terminology introduced in ENG 103. Narrative is not just an specialised literary concept, but a form of discourse found in everyday language usage, giving rise to such mundane and apparently trivial uses of language as gossip, anecdotes and jokes. It is, in fact, one of the most fundamental uses of language known to humans. For this very reason, narrative - or, put more simply, "telling a story" - could also be the first of the writing skills to be covered in ENG 104, the "language" module. Here students could test their own skills at producing a narrative. This could take a number of forms: perhaps writing an alternative ending to a literary work studied in the previous module, or creating a narrative from an existing text dealing with a related topic (re-writing a comic strip as a prose narrative; writing the "story" behind a newspaper report, and so on).

Alternatively, or additionally, the link between literature and student writing could be made through common topics, themes or content.

Writing skills can be further developed from this base, through extension activities. For example, themes found in literary texts and the students' own narrative writing could provide the rough data for the planning and writing of an argumentative essay: here, the concrete world of the narrative has to be translated into more abstract, objective discourse.

The literary texts as well as the students' own writing can then provide meaningful and motivating contexts for the study of the grammatical forms and functions. ${ }^{2}$

\section{Initial response from students and lecturers}

The teaching of the first year modules was initially undertaken by two lecturers, a colleague and I. Teaching was by means of lectures and

2 For particular applications of some of the principles outlined in this section, see Butler (1999, 2000, 2001). 
tutorials; students were also expected to work on their own to cover material not examined in detail in class. While the number of students registered for each module was, on average, 120 students, this system was workable, although not ideal. In 2001 a sudden (and unprepared for) increase in student numbers at the University brought the first year class to a number in excess of 350 students. The crisis, however, provided the Department with an opportunity for further development to the new undergraduate programme. It also enabled me to extend my research in a direction only touched upon before. The students were divided into groups of approximately twenty-five, and the teaching was shared by all members of the Department in an experiment in collaborative teaching. It soon became clear that teaching in small groups enabled lecturers to maximise on the benefits already apparent in the integration of language and literature. This is in line with the views of most writers in the field: Carter and Long (1987:1), for example, mention that their learning techniques and exercises "often involve active group and pair work in class"; Maley and Duff (1989:3) also emphasise the need to work in pairs in all small groups because "ideas seem to flow best when they are exchanged".

In the course of 2000 and 2001 I attempted to gauge the views of lecturers and students on the two important principles underlying the first year modules: language/literature integration and teaching/learning in tutorials or small groups. This information was gathered by means of questionnaires, interviews and (in the case of students) self-reflective tasks. The findings indicate a remarkable unanimity of opinion in favour of both principles by lecturers and students. There would seem to be a clear mandate to continue with the approach that the Department has adopted.

In the questionnaire given to the lecturers, nine respondents, most of whom were teaching the English 100 modules for the first time, were asked to comment on the validity of claims about the benefits of language/literature integration. They were asked to draw on their recent experiences in teaching the modules and indicate whether they agreed, disagreed, or are not able to comment. The claims were expressed in the fourteen statements listed below: they represent my attempt to identify common ground in the literature in the field. Following the lead by Tomlinson (1985) and Carter (1985) I have divided them into two groups, Language through literature and Literature through language:

\section{Language through literature}

1. Literature provides a resource/authentic context for the teaching of grammar and vocabulary. 
2. Because of its appeal to the learner's imagination and emotions, literature provides motivation for language learning.

3. The themes and plots of literary works provide stimuli for meaningful debates, discussions and other language tasks which develop the learner's linguistic and communicative competence.

4. Literature provides learners with authentic models for the norms of language use.

5. Literature assists learners in developing their overall language awareness and knowledge about language.

6. The study of literature helps develop the learner's interpretive and analytical skills (e.g. skills of inference) which can be applied to other language-related activities.

7. Literature represents language "at its best" and thus provides an ideal model for language learning.

8. Literature provides learners with insights into the norms and cultural values embodied in the language.

9. The study of literature educates the "whole person" in a way that more functional approaches to language teaching do not.

\section{Literature through language}

10. Comparing literary and "non-literary" texts allows the learner to move from the known to the unknown: in this way literature is made more accessible to him/her.

11. Linking the study of literary texts to creative language activities (such as rewriting endings to stories, role playing, rewriting a narrative from a different point of view or in a different genre) makes the text more accessible to the learner and removes some of the intimidating mystique that often surrounds literature.

12. Applying basic ESL/EFL techniques (such as cloze, multiple choice and jigsaw reading) to the study of literature develops language skills and promotes engagement with the text.

13. Learners cannot develop literary competence without an adequate competence in language. Integration of language and literature helps compensate for any inadequacies in the learner's linguistic competence.

14. Developing the learner's sensitivity to how language is used in a literary text (e.g. through elementary stylistic analysis) provides 
him/her with a "way in" to the text, a starting point for the process of comprehension and appreciation.

Here, as in their overall responses to the questionnaire, there was significant agreement among the respondents. The number of responses in agreement with each of the statements never fell below seven. In a number of instances agreement was unanimous (statements 4, 6, 11, 14); in others, rather than expressing disagreement, respondents indicated that they were not able to comment (statements 5, 8, 9, 10, 12, 13). Only in four instances did respondents explicitly disagree with the statement (statements 1,2, 3, 7). For statements 1-3 disagreement in each case was expressed by the same respondent. Eight of the nine respondents indicated their desire to continue as part of the team teaching the modules.

Responses from students indicated a similar appreciation for the integration of language and literature. Here are a few of their comments:

- It is helpful and interesting not to focus on one aspect of the language. It broadens the knowledge of the learner and encourages creativeness.

- Sometimes literature can be viewed as grammar put into practice. ... All the grammar work we do in class can be noticed in literature. Personally sometimes different forms of grammar we do in class can be confusing (articles, punctuation, sentence construction etcetera), but as I read through my literature work I can understand better.

- ... there is no way how one can clearly express her/himself in literature without the right grammar. It also breaks the monotony of doing one thing over a period of time.

\section{Conclusion}

Markee (1997:15) makes the obvious, but necessary point that educational organizations are, by their very nature, "transient institutions". Students graduate, staff move on to other jobs. This kind of instability is "the norm, not the exception", but it does have an effect on any curricular innovations.

Unfortunately the current mood of uncertainty in South African education does nothing to provide the stability that should underlie the "normal" flux of teaching and learning. It is here that action research, with its conception of the teacher as researcher engaged in a continuous cycle of action, reflection and self-evaluation (Walker, 1989:51), has a valuable role to play. Integrating language and literature in the English programme 
at the University of North West represented an attempt to give practical and concrete expression to the potential for interface between the two disciplines, in a way that would promote the educational goals of the Department. The implementation and initial evaluation of the programme, briefly described here, have been elements in an attempt to follow through, develop and refine upon that initial intervention. Nor has the process ended here: changing circumstances, needs and perceptions will determine how we, as teachers of language and literature, continue to act and reflect.

This article began with two quotations: one from an academic and one from a student; it seems appropriate therefore that it should conclude with the voice of a teacher. The following comment was made by a colleague in one of her responses to the questionnaire. Asked if she was willing to continue her involvement in the ENG 100 experiment, she responded:

I think I feel part of the English Department, that I am a member who can also make a difference. Again, I feel revived and fulfilled that at long last, I am teaching what I have been trained to teach.

\section{Bibliography}

Allen, V.F. 1976. Some insights from linguistics for the teaching of literature. English Teaching Forum, 14(4):17-21, Oct.

Arthur, B. 1968. Reading literature and learning a second language. Language Learning, 18(3 \& 4):199-210.

Bassnett, S. \& Grundy, P. 1993. Language through literature: Creative language teaching through literature. Harlow : Longman.

Bates, M. 2000. A poet's view: From hats to socks. IATEFL Issues, 157:13.

Blatchford, C.H. 1972. ESOL and literature: A negative view. Culture and Language Learning Newsletter, 1(4):1, 6, 7.

Brumfit, C.J. (ed.) 1983. Teaching literature overseas: language based approaches. ELT Documents 115. London : Pergamon Press in association with the British Council.

Brumfit, C.J. \& Carter, R. 1986. Literature and language teaching. Oxford : Oxford University Press.

Butler, I. 1999. Integrating language and literature. Folio: Journal of the Materials Development Association, 5(2):3-40.

Butler, I. 2000. We have to talk about these things: AIDS and ESL in South Africa. IATEFL Global Issues, 1/00(9): 5-9, March.

Butler, I. 2001. To teach and delight: Literature in the language classroom. IATEFL Issues, 161: 4-5, June-July.

Carter, R. 1985. Language through literature and literature through language. EFL Gazette: 9, March.

Carter, R. \& Long, M.N. 1987. The web of words. Cambridge : Cambridge University Press.

Carter, R. \& Long, M.N. 1991. Teaching literature. Harlow : Longman. 
Carter, R., Walker, R. \& Brumfit, C. (eds.) 1989. Literature and the learner: Methodological approaches. ELT Documents 130. London : Modern English Publications in association with the British Council.

Chapman, M.J.F. 1990. Intervention and change: the teaching of literature in South Africa. South African Journal of Higher Education. Special Edition: 136-38.

Cohen, L. \& Manion, L. 1994. Research methods in education. Fourth Edition. London: Routledge.

Collie, J. \& Slater, S. 1987. Literature in the language classroom. Cambridge : Cambridge University Press.

Combrink, A.L. 1996. What is stylistics and why are we saying such nice things about it? Paper delivered to the Department of English, University of North West, Mafikeng (September).

Duff, A. \& Maley, A. 1990. Literature. Resource Books for Teachers. Oxford : Oxford University Press.

Lazar, G. 1993. Literature and language teaching. Cambridge : Cambridge University Press.

Lazar, G. 1994. Using literature at lower levels. ELT Journal, 48(2):115-124.

Maley, A. \& Duff, A. 1989. The inward ear: Poetry in the language classroom. Cambridge : Cambridge University Press.

Marckwardt, A.H. 1978. The place of literature in the teaching of English as a second language. Honolulu : University Press of Hawaii.

Markee, N.1997. Managing curricular innovation. Cambridge : Cambridge University Press.

McRae, J. 1991. Applying the buzzwords: Literature for language learners. British Book News: 432-437, July.

McRae, J. 1997. Literature with a small 'l'. London : Prentice Hall.

Murray, S. 1990. Teaching English for academic purposes (EAP) at the University of Bophuthatswana. South African Journal of Higher Education. Special Edition:132-142.

Norman, R. 1998. English language and literature: An integrated approach. Cheltenham : Stanley Thornes.

Nunan, D. 2001. Action research in language education. In: Hall, D.R. \& Hewings, A. (eds.) Innovation in English language teaching: A Reader. London : Routledge. p. 197-207.

Orr, M. 1997. Evolution or mutation? Conference report on the Committee of Professors of English (COPE) First Year Forum, University of Cape Town, January 1997. Scrutiny 2, 2(1):51-54.

Paran, A.1998. Helping learners to create and own literary meaning in the ELT classroom. Ideas: The APIGA Magazine, 1:6-9.

Pereira, E. 1990. Introduction to the proceedings. South African Journal of Higher Education. Special Edition: 114-115.

Pope, R. 1998. The English Studies Book. London : Routledge.

Saunders, W. 1991. On the reading of English in black education, and the teaching of poetry and Shakespeare (new texts for old). Unpublished paper presented at SAALA conference, University of Witwatersrand (July).

Simpson, P. 1997. Language through literature: An introduction. Interface series. London : Routledge.

Stern, S.L. 1991. An integrated approach to literature in ESL/EFL. In: Celce-Mercia, M. (ed.) Teaching English as a second or foreign language. Second Edition. Boston : Heinle \& Heinle. p. 328-346. 
Tomlinson, B. 1985. Language through literature and literature through language. EFL Gazette: 9, March.

University of Bophuthatswana. 1980. University of Bophuthatswana. Its aims, goals and structure. Mafikeng : University of Bophuthatswana. (Information Brochure 1.)

Walker, M. 1989. Action Research as a project. Cape Town : University of Cape Town.

Widdowson, H.G. 1975. Stylistics and the teaching of literature. Harlow : Longman.

Widdowson, H.G. 1992. Practical stylistics: an approach to poetry. Oxford : Oxford University Press.

Yin, R.K. 1994. Case study research: Design and methods. Second Edition. London : Sage.

\section{Key concepts:}

English as a second language teaching language teaching literature integration of language and literature

\section{Kernbegrippe:}

Engels as tweede taal taalonderrig literatuuronderrig integrasie van taal en literatuur 